Check for updates

Cite this: RSC Adv., 2019, 9, 21009

Received 19th April 2019

Accepted 19th June 2019

DOI: 10.1039/c9ra02952d

rsc.li/rsc-advances

\section{Construction of $\mathrm{LiMn}_{2} \mathrm{O}_{4}$ microcubes and spheres via the control of the (104) crystal planes of $\mathrm{MnCO}_{3}$ for high rate Li-ions batteries}

\author{
Yanshen Gao, Xinlu Wang, (D) Wensheng Yu, Guixia Liu, (D) Xiangting Dong (DD \\ and Jinxian Wang (iD*
}

\begin{abstract}
We have studied a synthetic route to control the morphology of $\mathrm{MnCO}_{3}$ precursors. Taking the (104) crystal planes in the structure of $\mathrm{MnCO}_{3}$ as the research point, the hydrothermal method was used to synthesize $\mathrm{MnCO}_{3}$ cubes with highly exposed (104) crystal planes and densely crystallized $\mathrm{MnCO}_{3}$ spheres by changing the water-ethanol reaction system. The $\mathrm{MnCO}_{3}$ cubes and spheres were used as self templates to prepare spinel $\mathrm{LiMn}_{2} \mathrm{O}_{4}$ by thermal decomposition and topological crystallization. The formation mechanism of $\mathrm{MnCO}_{3}$ and $\mathrm{LiMn}_{2} \mathrm{O}_{4}$ was analyzed using characterization methods such as X-ray diffraction, scanning electron microscopy and high-resolution transmission electron microscopy. Electrochemical tests evidenced that the electrochemical performance of the as-made cubic and spherical $\mathrm{LiMn}_{2} \mathrm{O}_{4}$ significantly improved compared with that of pristine $\mathrm{LiMn}_{2} \mathrm{O}_{4}$. The results manifested that the $\mathrm{LiMn}_{2} \mathrm{O}_{4}$ cubes and spheres have superior discharge capacity, delivering first discharge capacities of 130 and $115.1 \mathrm{~mA} \mathrm{~h} \mathrm{~g}^{-1}$ at $0.5 \mathrm{C}$, and 96.4 and $88.3 \mathrm{~mA} \mathrm{~h} \mathrm{~g}^{-1}$ even at a high rate of 20C, respectively. After calculating the $\mathrm{Li}^{+}$diffusion coefficients of the samples, the results elicited that the diffusion ability of the $\mathrm{Li}^{+}$in the cubic and spherical $\mathrm{LiMn}_{2} \mathrm{O}_{4}$ was significantly improved.
\end{abstract}

\section{Introduction}

As a variety of lithium ion battery cathode material, spinel $\mathrm{LiMn}_{2} \mathrm{O}_{4}$ is one of the most promising candidates because of its low cost, low toxicity, and environmental friendliness. ${ }^{1-5}$ However, its low charge transfer rate and slow $\mathrm{Li}^{+}$diffusion ability result in poor rate performance, ${ }^{6-8}$ which seriously restricts the application of this material in hybrid electric vehicles. To the best of our knowledge, the rate performance is closely related to the charge transfer rate, and the charge transfer rate is limited by the diffusion of $\mathrm{Li}^{+}$in the material. ${ }^{9}$ The characteristic diffusion time of $\mathrm{Li}^{+}$is known from the equation $\tau=l^{2} / D,{ }^{9,10}$ which is proportional to the diffusion distance $(l)$ and inversely proportional to the $\mathrm{Li}^{+}$diffusion coefficient $(D)$. To reduce the diffusion time, either a shortened diffusion distance or increased diffusion coefficient is needed. The preparation of $\mathrm{LiMn}_{2} \mathrm{O}_{4}$ as a nano-material with a certain morphology is a method that can effectively shorten the diffusion distance between lithium ions. ${ }^{11}$ For example, it has been prepared as nanoparticles, ${ }^{12}$ nanowires, ${ }^{7}$ nanotubes, ${ }^{13}$ nanorods, ${ }^{\mathbf{1 4}}$ nanospheres, ${ }^{15}$ and so on. However, some nanomaterial shapes are complicated to prepare and may encounter some undesirable side reactions due to the high specific surface area

School of Chemistry and Environmental Engineering, Changchun University of Science and Technology, Changchun 130022, P. R. China. E-mail: wjx87@sina.com; Fax: +860431-85383815; Tel: $+86-18686684860$ in the operating environment of the batteries. ${ }^{15,16}$ Therefore, preparation of a porous micro-sized cathode material with a certain morphology is still one of the strategies for effectively improving the electrochemical performance.

Among the synthetic methods used to obtain a certain morphology, the hard template method and the self-template method have been most commonly used. The hard template method is costly to use and usually requires attention to the additional reaction against $\mathrm{LiMn}_{2} \mathrm{O}_{4} \cdot{ }^{17}$ For the self-template method, precursors with a certain morphology can be retained before and after the reaction. Among these synthesis strategies of $\mathrm{LiMn}_{2} \mathrm{O}_{4}, \mathrm{MnCO}_{3}$ is a relatively common reaction precursor. That is to say, $\mathrm{LiMn}_{2} \mathrm{O}_{4}$ produced using the selftemplate method commonly possesses a similar morphology to its corresponding precursor $\mathrm{MnCO}_{3}$ during the thermal decomposition and lithiation processes, which is reasonable and beneficial for controlling the structures of the final products.

To fabricate $\mathrm{MnCO}_{3}$ precursors, at present the hydrothermal/ solvothermal method and facile room temperature precipitation method are generally employed. ${ }^{\mathbf{1 8 - 2 4}}$ Rapid precipitation and aggregation usually leads to spherical shaped $\mathrm{MnCO}_{3}$. Besides this, Huang et $a .^{21}$ explored the $\mathrm{pH}$ value of the precipitation system and prepared cubic and spherical $\mathrm{MnCO}_{3}$ precursors. Wu et al. ${ }^{22}$ fabricated $\mathrm{LiMn}_{2} \mathrm{O}_{4}$ from cubic $\mathrm{MnCO}_{3}$ and spherical $\mathrm{MnCO}_{3}$ precursors by adding cetyl trimethylammonium bromide (CTAB) and adjusting the $\mathrm{pH}$ value of the 
precipitation system. However, in order to ensure uniform precipitation of the precursor, the precipitation temperature and the $\mathrm{pH}$ value must be strictly controlled, and the $\mathrm{pH}$ value boundary between the two morphologies is narrow.

$\mathrm{MnCO}_{3}$ is similar in structure to $\mathrm{CaCO}_{3}$, one of the most widely studied biominerals, as they belong to the same $\mathbf{M C O}_{3}$ ( $\mathrm{M}=\mathrm{Ca}, \mathrm{Mn}, \mathrm{Ba}$, etc. $)$ crystalline type. Generally, polycrystalline biominerals exhibit various morphologies, with small crystal building blocks that can be used to compose complex structures. ${ }^{25,26}$ Herein, the most common $\mathrm{CaCO}_{3}$ crystal morphology is calcite-type rhombohedra, ${ }^{27}$ with the characteristic (104) crystal planes of the morphology having the lowest surface energy. ${ }^{28}$ Additives can be adsorbed onto the specific crystal planes of nanocrystals, thus changing the subsequent aggregation process. ${ }^{29}$ In particular, some organic substances (for example, ethanol) have strong interactions between the (104) crystal planes. ${ }^{27,30-34}$ Based on the relative theories above, we prepared a $\mathrm{MnCO}_{3}$ cube precursor with highly exposed (104) crystal planes using a hydrothermal method without strict control of the $\mathrm{pH}$ and the addition of a structure directing agent, and changed the crystal stacking mode by simply adding ethanol solvent into the spherical material without changing the other conditions. The corresponding microporous cubic and spherical $\mathrm{LiMn}_{2} \mathrm{O}_{4}$ materials were then obtained by selftemplated thermal decomposition and lithiation reactions and used as cathode materials for lithium ion batteries, wherein the cubic and spherical $\mathrm{LiMn}_{2} \mathrm{O}_{4}$ exhibited good cycling performance and rate performance, and the lithium ion diffusion ability was significantly improved. We have also discussed in detail the formation mechanism of the morphological diversity of $\mathrm{MnCO}_{3}$ and $\mathrm{LiMn}_{2} \mathrm{O}_{4}$.

\section{Experimental}

\subsection{Synthesis of $\mathrm{MnCO}_{3}$ cubes and spheres}

The cubic and spherical $\mathrm{MnCO}_{3}$ precursors were prepared using a hydrothermal method. Firstly, $1 \mathrm{mmol}$ of $\mathrm{MnSO}_{4} \cdot \mathrm{H}_{2} \mathrm{O}$ and $0.1 \mathrm{~mol}$ of urea were dissolved in $120 \mathrm{~mL}$ of deionized water, and then $80 \mathrm{~mL}$ of the solution mixture was transferred into a $100 \mathrm{~mL}$ Teflon-lined stainless-steel autoclave. The sealed reactor was maintained at $150{ }^{\circ} \mathrm{C}$ for $10 \mathrm{~h}$ and then cooled down to ambient temperature. After filtration, the precipitate was washed four times with deionized water and ethanol, then dried at $120{ }^{\circ} \mathrm{C}$ over $12 \mathrm{~h}$ to obtain the $\mathrm{MnCO}_{3}$ cubes. The preparation of the $\mathrm{MnCO}_{3}$ spheres was similar to that of the $\mathrm{MnCO}_{3}$ cubes, using the same amounts of $\mathrm{MnSO}_{4}$ and urea, reaction temperature and time as those of the $\mathrm{MnCO}_{3}$ cubes. The only difference was the use of mixed solvents $(72 \mathrm{~mL}$ of distilled water and $48 \mathrm{~mL}$ of ethanol to dissolve $\mathrm{MnSO}_{4}$ and urea). After the solvothermal reaction, the precipitated product was also washed and dried using the same conditions as those used to obtain $\mathrm{MnCO}_{3}$ spheres.

\subsection{Preparation of cubic and spherical $\mathrm{LiMn}_{2} \mathrm{O}_{4}$}

The two different morphologies of $\mathrm{MnCO}_{3}$ were pre-sintered at $550{ }^{\circ} \mathrm{C}$ for $3 \mathrm{~h}$ for conversion into $\mathrm{Mn}_{2} \mathrm{O}_{3}$. Thereafter, the oxide powders were mixed with $\mathrm{Li}_{2} \mathrm{CO}_{3}\left(\mathrm{Li}_{2} \mathrm{CO}_{3}: \mathrm{Mn}_{2} \mathrm{O}_{3}=0.54: 1\right.$, molar ratio) and then at $750{ }^{\circ} \mathrm{C}$ for $12 \mathrm{~h}$ in the air to obtain the final cubic and spherical $\mathrm{LiMn}_{2} \mathrm{O}_{4}$ products, respectively.

\subsection{High temperature solid state preparation of pristine $\operatorname{LiMn}_{2} \mathrm{O}_{4}$}

$\mathrm{MnO}_{2}$ and $\mathrm{Li}_{2} \mathrm{CO}_{3}$ were weighed according to the stoichiometric ratio, carefully ground and uniformly mixed, and then placed in a high-temperature tube furnace and calcined at a temperature of $750{ }^{\circ} \mathrm{C}$ for $12 \mathrm{~h}$ to obtain pristine $\mathrm{LiMn}_{2} \mathrm{O}_{4}$.

\subsection{Characterization}

The structures of the prepared materials were characterized by X-ray diffractometer (TD-3000, Dandong Tongda Co, LTD, China) equipped with a $\mathrm{Cu} \mathrm{K} \alpha$ radiation source with continuous scanning in the $2 \theta$ range of $10-90^{\circ}$, at a scan rate of $0.02^{\circ}$ per minute. Morphological characterization of the hydrothermal precursors and final calcined products was achieved by scanning electron microscopy (SEM, JMS-7610F, JEOL), and highresolution transmission electron microscopy (HRTEM: JEM$2100,180 \mathrm{kV}$ ). The final products were assembled into CR2032 coin-cell type batteries and their electrochemical performances were tested. The cathode material slurry was composed of $70 \mathrm{wt} \%$ active materials, $20 \mathrm{wt} \%$ acetylene black and $10 \mathrm{wt} \%$ polyvinylidene fluoride in $N$-methyl-2-pyrrolidone, carefully mixed and uniformly coated onto aluminum foil and then vacuum dried at $120{ }^{\circ} \mathrm{C}$ for $12 \mathrm{~h}$. Lithium metal foil was used as the battery anode material and $\mathrm{LiPF}_{6}$ as the electrolyte, and the assembly was carried out in an argon filled glove box, keeping the oxygen and moisture content under $0.01 \mathrm{ppm}$. The electrochemical performances of the test cells were measured using a battery testing system (BTS-5 V/10 mA, Neware Technology Limited Corporation, China) over a cycling voltage range of 3.0$4.5 \mathrm{~V}$ and rate voltage range of $3.0-4.3 \mathrm{~V} .\left(1 \mathrm{C}=148 \mathrm{~mA} \mathrm{~h} \mathrm{~g}{ }^{-1}\right)$. Electrochemical impedance measurements were conducted using an electrochemical workstation (CHI-760D, Shanghai Chenhua Instrument Limited Corporation, China) over a frequency range of $0.01 \mathrm{~Hz}$ to $100 \mathrm{kHz}$. The impedance fitting was accomplished utilizing Zview software, limiting the systematic error of the calculations to under $10 \%$.

\section{Results and discussion}

Cubic and spherical $\mathrm{LiMn}_{2} \mathrm{O}_{4}$ were prepared using a hydrothermal and temperature solid phase method. A schematic diagram of the preparation method is shown in Fig. 1.

The following chemical reactions mainly occur in the hydrothermal process: $:^{35}$

$$
\begin{gathered}
\mathrm{NH}_{2} \mathrm{CONH}_{2}+\mathrm{H}_{2} \mathrm{O} \rightarrow 2 \mathrm{NH}_{3}+\mathrm{CO}_{2} \\
\mathrm{NH}_{3}+\mathrm{H}_{2} \mathrm{O} \rightarrow \mathrm{NH}_{4}^{+}+\mathrm{OH}^{-} \\
\mathrm{CO}_{2}+2 \mathrm{OH}^{-} \rightarrow \mathrm{CO}_{3}^{2-}+\mathrm{H}_{2} \mathrm{O} \\
\mathrm{CO}_{3}{ }^{2-}+\mathrm{Mn}^{3+} \rightarrow \mathrm{MnCO}_{3}
\end{gathered}
$$




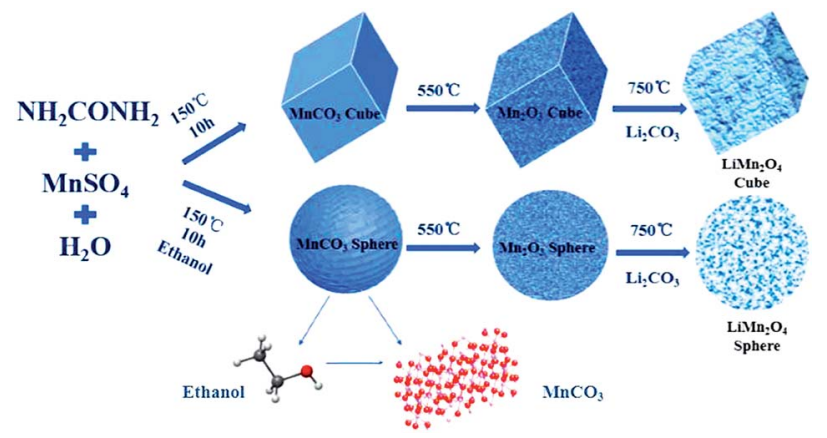

Fig. 1 Schematic of the preparation process of the cubic and spherical $\mathrm{LiMn}_{2} \mathrm{O}_{4}$ products.
In the first hydrothermal step shown in Fig. 1, $\mathrm{MnSO}_{4}$ provides $\mathrm{Mn}^{2+}$ ions for the reaction, and urea acts as a precipitant. When the solvent is pure water, the macroscopic morphology of the $\mathrm{MnCO}_{3}$ precipitate was cubic after the reaction. In contrast, after adding ethanol into the pure water reaction system, a series of reactions occurred that led to a final product of $\mathrm{MnCO}_{3}$ spheres. The XRD characterization of the hydrothermal products derived from different solvent systems is shown in Fig. 2a.

The typical characteristic peaks of $\mathrm{MnCO}_{3}$ are shown in Fig. 2a. The prepared $\mathrm{MnCO}_{3}$ cubes and spheres are in the $R \overline{3} \mathrm{~m}$ space group, and can be well indexed to PDF\#44-1472. The average crystallite sizes of the $\mathrm{MnCO}_{3}$ cubes and spheres were
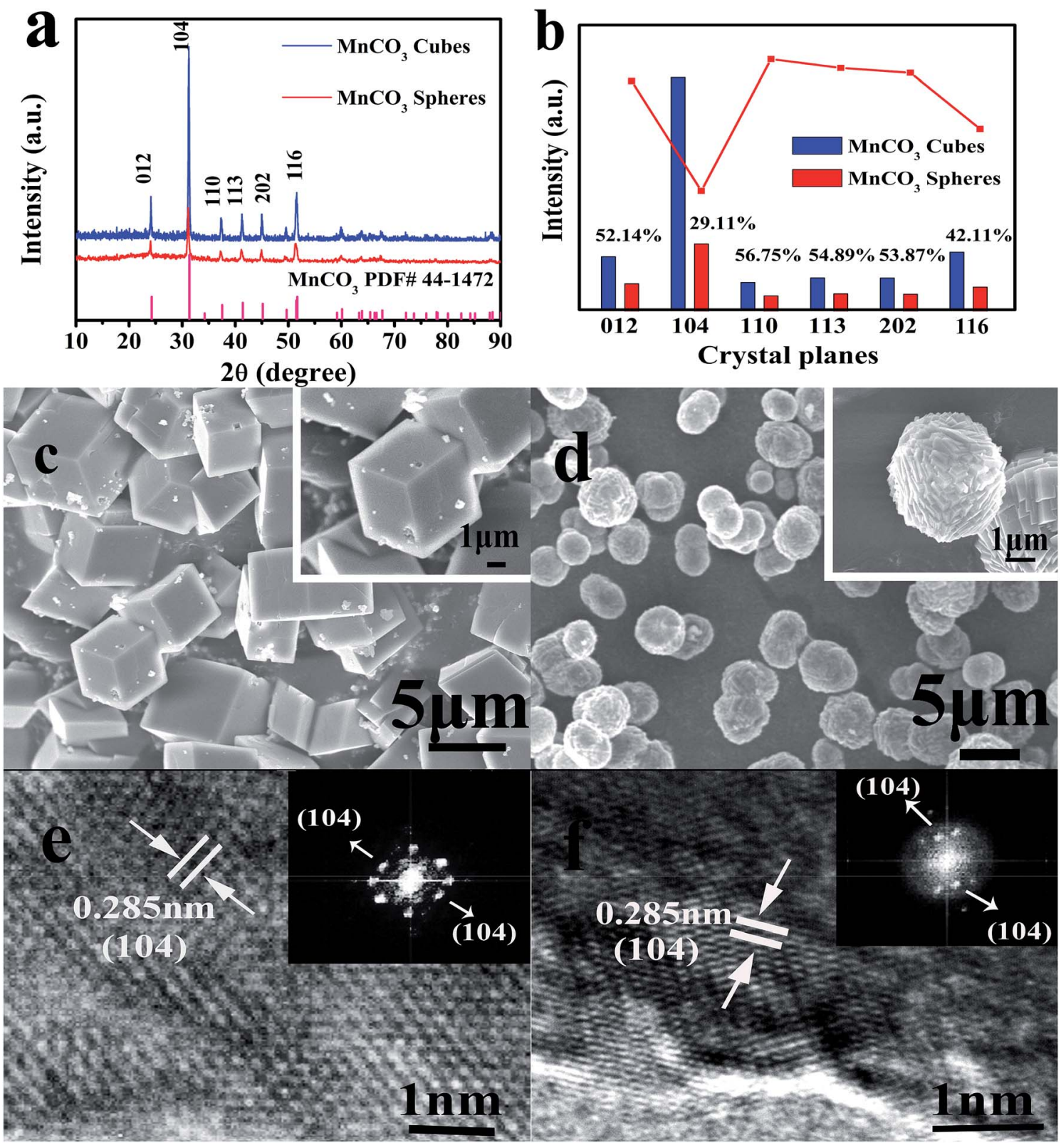

Fig. 2 Characterization of the $\mathrm{MnCO}_{3}$ cubes and spheres. (a) X-ray diffraction (XRD) patterns of the $\mathrm{MnCO}_{3}$ cubes and spheres. (b) XRD characteristic peak intensity comparison of the cubic and spherical $\mathrm{MnCO}_{3}$. SEM images of the $\mathrm{MnCO}_{3}$ (c) cubes and (d) spheres. HRTEM and Fast Fourier Transform (FFT, inset) images of the $\mathrm{MnCO}_{3}$ (e) cubes and (f) spheres. 
calculated by the Debye-Scherrer equation from the full width half maximum (FWHM) of the XRD diffraction peaks and were found to be 42.8 and $34.6 \mathrm{~nm}$ for the cubes and spheres, respectively. Due to the heteromorphism of carbonate minerals, vaterite usually exhibits a spherical morphology, ${ }^{26}$ but in this experiment, the addition of ethanol did not affect the overall crystal structure. In the meantime, as shown in the histogram of Fig. $2 \mathrm{~b}$, combining the results of $I_{\text {Spheres }} / I_{\text {Cubes }}$ in the inset, the intensity of the XRD characteristic peaks of the $\mathrm{MnCO}_{3}$ spheres after ethanol participation was remarkably lowered, especially for the (104) crystal planes. For the $\mathrm{MnCO}_{3}$ crystal, its structure and crystal growth pattern are similar to those of $\mathrm{CaCO}_{3}$. Among the numerous crystal planes of $\mathrm{MnCO}_{3}$, the (104) crystal planes are the characteristic crystal planes, ${ }^{36}$ composed of $\mathrm{Mn}^{2+}$ and $\mathrm{CO}_{3}{ }^{2-}$, densely distributed, and have the lowest surface energy. According to the Bravais law, ${ }^{37}$ the crystal growth rate is inversely proportional to the density of the surface network. During the growth of the $\mathrm{MnCO}_{3}$ cubes, the growth direction is mainly in the direction of the vertical (104) crystal planes. After the crystal growth is completed, the crystal planes are completely retained, and the morphology of the final product is a thermodynamically stable calcite rhombohedral crystal, as shown in Fig. 2c. In this formation process, the least dense phase is formed first and transforms to the next stage phase, and finally, the most dense phase, which is the most stable phase. This kinetic transformation process is strictly in order of increasing thermodynamic stability. ${ }^{29}$ The energy changes during the formation follow Wolfgang Ostwald's "steps rule". ${ }^{38}$ The dense surface of the block is smooth and the particle size is $2-5 \mu \mathrm{m}$.

Fig. 2d shows $\mathrm{MnCO}_{3}$ spheres prepared using a mixed solution system of ethanol and water under the same reaction conditions. It can be observed that the spheres mainly feature the stacking of cubic blocks. Herein, we have analyzed the formation process of the $\mathrm{MnCO}_{3}$ spheres. When ethanol is added at the beginning of the hydrothermal reaction, the overall viscosity of the system changes first, which can be described by the exponential expression: ${ }^{39}$

$$
\eta=\eta_{\mathrm{IL}} \exp \left[-x_{\mathrm{c}} / a\right]
$$

and the diffusion of ions follows the Stokes-Einstein equation: ${ }^{35}$

$$
D=R T / 6 \pi \eta r
$$

In eqn (5), $x_{\mathrm{c}}$ is the mole fraction of water, $\alpha$ is a characteristic constant of the mixture, and $\eta_{\mathrm{IL}}$ is the viscosity of the pure ionic liquid..$^{39}$ In eqn (6), $D$ is the diffusion constant, $\eta$ is the solution viscosity, and $r$ is the particle radius. ${ }^{35}$ It can be seen from eqn (6) that the diffusion coefficient is proportional to the reciprocal of the liquid viscosity, and ethanol plays a role in the crystallization process. In the hydrothermal reaction, when $\mathrm{MnCO}_{3}$ is precipitated, the ethanol molecules in the solution instantaneously adsorb to the precipitated $\mathrm{MnCO}_{3}$, especially to the (104) crystal planes of $\mathrm{MnCO}_{3}$. The mechanism is shown in Fig. 3. Fig. 3a shows the overall effect of ethanol molecules on the $\mathrm{MnCO}_{3}$ crystals, where the red planes in Fig. $3 \mathrm{~b}$ are the $\{104\}$ planes of the $\mathrm{MnCO}_{3}$ crystal. The hydrophilic hydroxyl group of the ethanol molecule strongly interacts with the oxygen on the (104) crystal planes, and at the same time, the hydrophobic group $-\mathrm{CH}_{3}$ is exposed to the outside to form an extremely stable and orderly hydrophobic adsorption layer. ${ }^{27,31,33}$ The existence of the adsorption layer seriously reduces the growth ability of the (104) crystal planes in the vertical direction, ${ }^{30}$ changes the surface energy and the $\mathrm{MnCO}_{3}$ particles gradually undergo directional crystallization, and the blocks are densely packed into spheres. Also, the hydroxyl group is present in the pure water reaction system, where the lowest surface energy is stabilized, especially if its adsorption capacity is insufficient to change the equilibrium shape. ${ }^{40}$ Therefore, the addition of ethanol plays an important role in the morphology control.

The $\mathrm{MnCO}_{3}$ precursor of the obtained sample was further examined by high resolution transmission electron microscopy (HRTEM) and its Fast Fourier transform (FFT) pattern was recorded. From the HRTEM images of the lattice fringes (Fig. 2e and $\mathrm{f}$ ), a lattice distance of $0.285 \mathrm{~nm}$ can be observed, which is
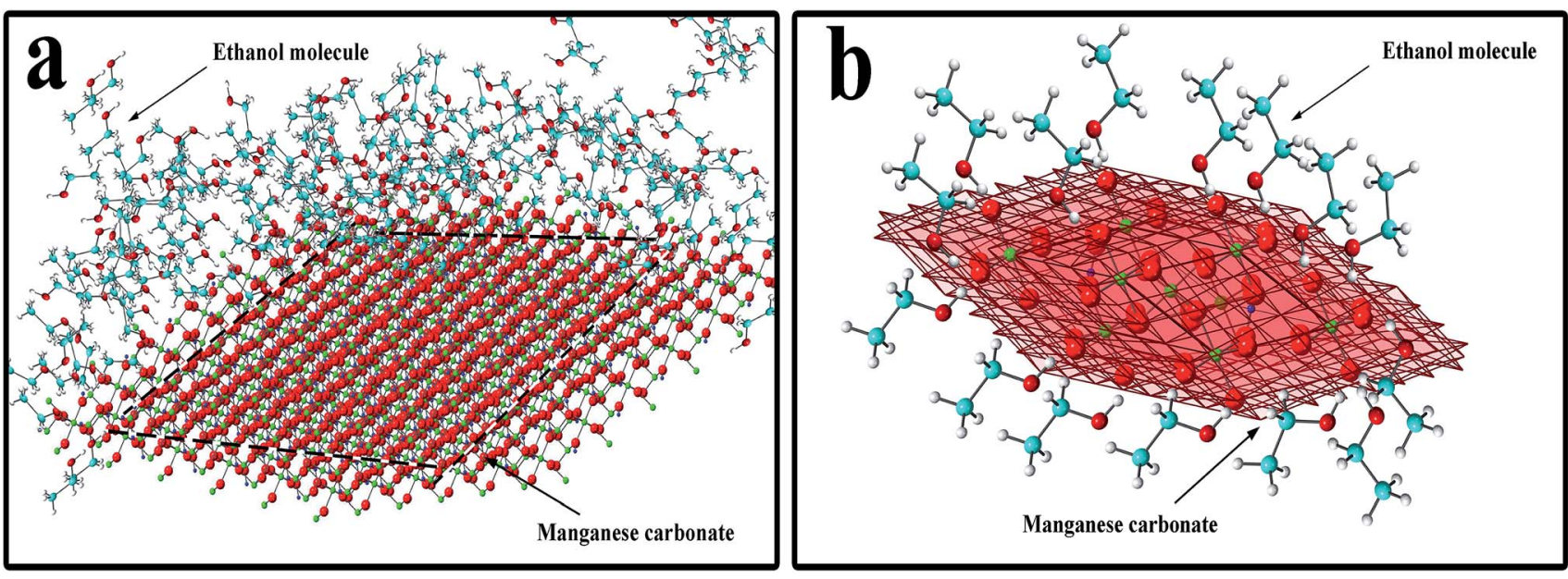

Fig. 3 Schematic of the effects of the ethanol molecules and $\mathrm{MnCO}_{3}$ crystals. (a) The overall effect of the ethanol molecules on the $\mathrm{MnCO} 3$ crystals. (b) Effects of the ethanol molecules on the $\mathrm{MnCO}_{3}\{104\}$ crystal planes. The oxygen atoms are shown in red; manganese, green; hydrogen, titanium white; and carbon, lake blue or indigo. 
in squares showing the $d$-spacing of the (104) crystal planes of the $\mathrm{MnCO}_{3}$ and the highly crystalline crystals have a relatively regular boundary. From the FFT pattern studies, it is apparent that the crystallinity of the product obtained by adding ethanol is reduced in quality. This result is in agreement with the XRD analysis.

The chemical reaction equation for the calcining of the $\mathrm{MnCO}_{3}$ precursor in an air atmosphere at $550{ }^{\circ} \mathrm{C}$ is as follows: ${ }^{15}$

$$
\begin{gathered}
2 \mathrm{MnCO}_{3}+\mathrm{O}_{2} \rightarrow 2 \mathrm{MnO}_{2}+2 \mathrm{CO}_{2} \\
2 \mathrm{MnO}_{2} \rightarrow \mathrm{Mn}_{2} \mathrm{O}_{3}+0.5 \mathrm{O}_{2}
\end{gathered}
$$

The final product was obtained by calcining the manganese oxide with $\mathrm{Li}_{2} \mathrm{CO}_{3}$ at $750{ }^{\circ} \mathrm{C}$ in air, and their corresponding XRD patterns are shown in Fig. 4 . The diffracted characteristic peaks of the $\mathrm{LiMn}_{2} \mathrm{O}_{4}$ cubes, spheres and pristine sample are completely coincident with those of spinel $\mathrm{LiMn}_{2} \mathrm{O}_{4}$ (PDF\#350782), and there is no impurity phase detected, with ideal crystallinity. Fig. 5a and b show the SEM images of the $\mathrm{LiMn}_{2} \mathrm{O}_{4}$ cubes and $\mathrm{LiMn}_{2} \mathrm{O}_{4}$ spheres, respectively, and it can be seen that the particle size after calcination did not change significantly compared to the size before calcination. The surfaces of the $\mathrm{LiMn}_{2} \mathrm{O}_{4}$ cubes and $\mathrm{LiMn}_{2} \mathrm{O}_{4}$ spheres are rough and have a porous structure with a particle size of about $3 \mu \mathrm{m}$. Since the decomposition of the $\mathrm{Li}_{2} \mathrm{CO}_{3}$ during calcination releases $\mathrm{CO}_{2}$, the retention of the morphology of the final product is affected, but the morphology of most of the product is retained. The calcination process can be explained by a template formation mechanism. During the calcination process, $\mathrm{Li}_{2} \mathrm{CO}_{3}$ thermally decomposes to form $\mathrm{Li}_{2} \mathrm{O},{ }^{41}$ and $\mathrm{Li}_{2} \mathrm{O}$ undergoes a topological crystallization reaction with thermodynamically stable $\mathrm{Mn}_{2} \mathrm{O}_{3},{ }^{15}$ thereby largely retaining the morphology consistent with that of the precursor.

The HRTEM characterization and FFT patterns of the $\mathrm{LiMn}_{2} \mathrm{O}_{4}$ cubes and spheres were carried out and the results are shown in Fig. $5 c$ and d. Lattice fringes with a spacing of $0.48 \mathrm{~nm}$ can be observed, perfectly matching the distance between the

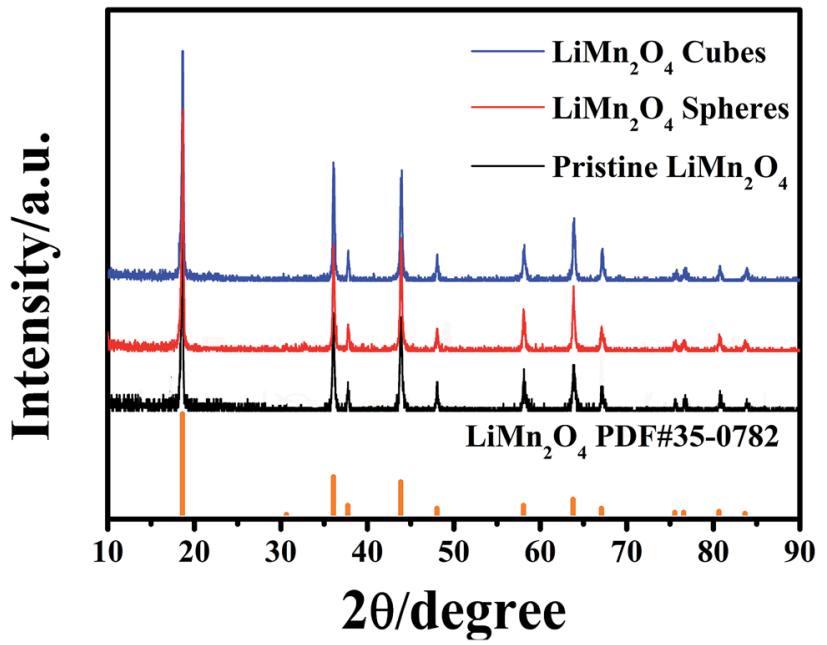

Fig. 4 XRD patterns of the $\mathrm{LiMn}_{2} \mathrm{O}_{4}$ cubes, spheres and pristine sample.

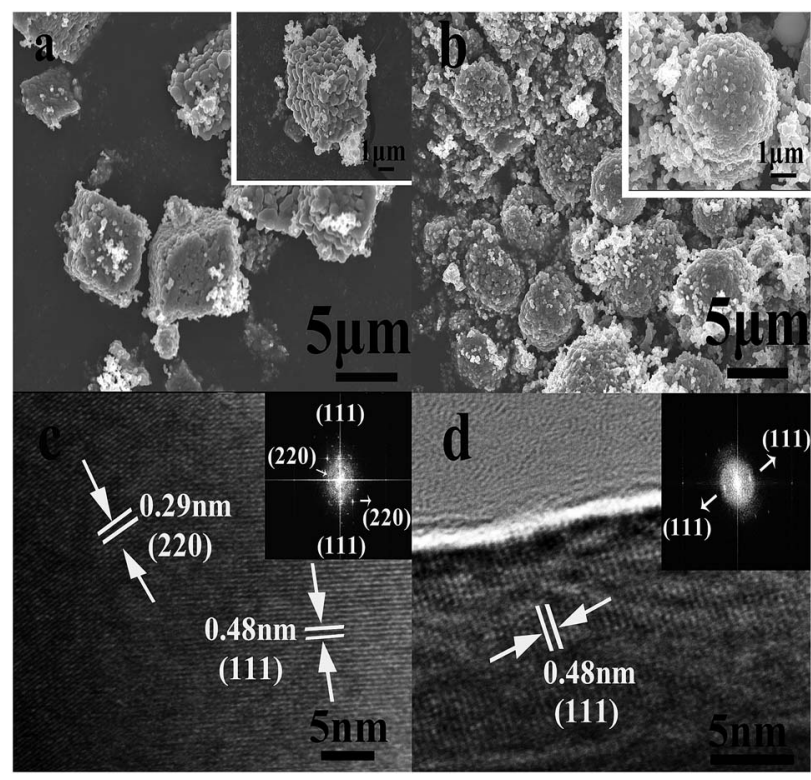

Fig. 5 SEM images of the $\mathrm{LiMn}_{2} \mathrm{O}_{4}$ cubes and spheres: (a) $\mathrm{LiMn}_{2} \mathrm{O}_{4}$ cubes, (b) $\mathrm{LiMn}_{2} \mathrm{O}_{4}$ spheres. HRTEM and fast Fourier Transform (FFT) images of the (c) $\mathrm{LiMn}_{2} \mathrm{O}_{4}$ cubes and (d) $\mathrm{LiMn}_{2} \mathrm{O}_{4}$ spheres.

(111) crystal planes of spinel $\mathrm{LiMn}_{2} \mathrm{O}_{4}$. Moreover, in the FFT patterns of the $\mathrm{LiMn}_{2} \mathrm{O}_{4}$ cubes and spheres, the $\mathrm{LiMn}_{2} \mathrm{O}_{4}$ cubes exhibit better crystallinity on the (111) crystal plane than the $\mathrm{LiMn}_{2} \mathrm{O}_{4}$ spheres. For spinel $\mathrm{LiMn}_{2} \mathrm{O}_{4}$, the crystal plane (111) facilitates $\mathrm{Li}^{+}$insertion/deinsertion behaviour, which increases the rate and cycling capabilities of spinel $\mathrm{LiMn}_{2} \mathrm{O}_{4}$, and the crystal plane (111) has lesser Mn dissolution and a more stable reconstructed surface structure. ${ }^{\mathbf{4 2 , 4 3}}$ Hence, the $\mathrm{LiMn}_{2} \mathrm{O}_{4}$ cubes show better electrochemical activity and stability than the $\mathrm{LiMn}_{2} \mathrm{O}_{4}$ spheres.

Fig. 6a and b show the morphology of pristine $\operatorname{LiMn}_{2} \mathrm{O}_{4}$ synthesized via a one-step high temperature solid state method. It can be observed that a large number of irregular aggregates exist due to the non-uniform crystallization in the sintering reaction.

Fig. 7a shows the cycling capabilities of the $\mathrm{LiMn}_{2} \mathrm{O}_{4}$ cubes, spheres, and pristine $\mathrm{LiMn}_{2} \mathrm{O}_{4}$ electrodes at a current density of $0.5 \mathrm{C}$ in the voltage range of $3.0-4.5 \mathrm{~V}$, where the $\mathrm{LiMn}_{2} \mathrm{O}_{4}$ cubes, spheres and pristine samples have first discharge capacities of 130, 115.1 and $106 \mathrm{~mA} \mathrm{~h} \mathrm{~g}^{-1}$, respectively. As shown in Fig. 7b, after 100 cycles, the capacity retention rates are $87.9 \%, 80.49 \%$, and $43.96 \%$, respectively. The first capacity was increased by

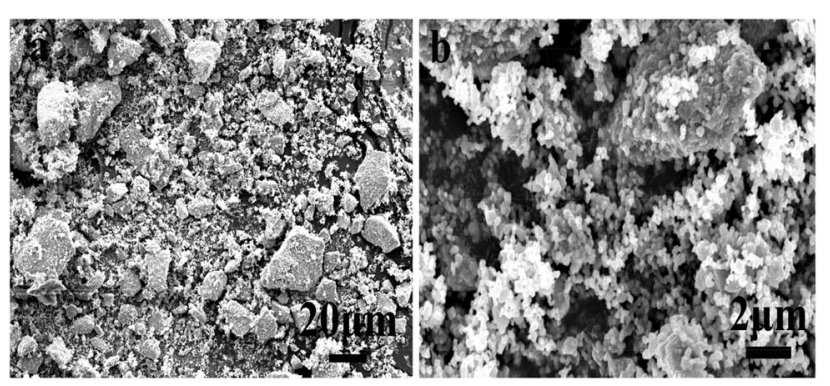

Fig. 6 SEM images of pristine $\mathrm{LiMn}_{2} \mathrm{O}_{4}$. 

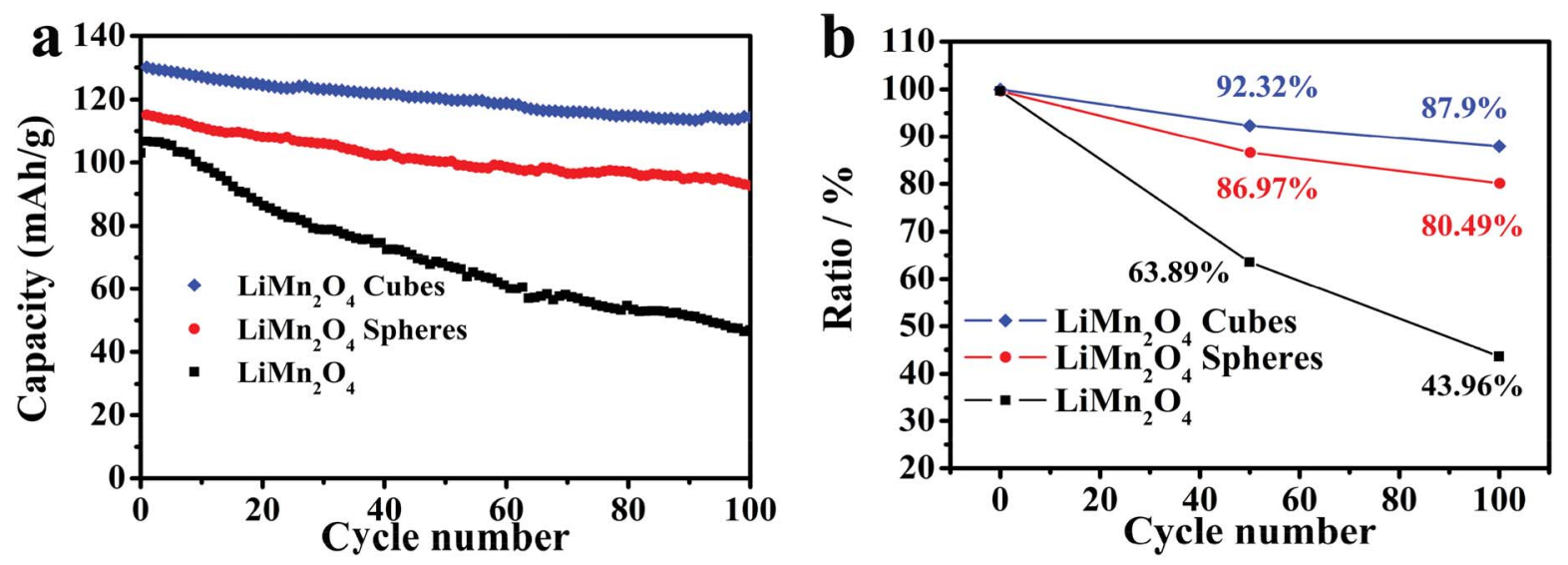

Fig. 7 (a) Cycling performance of the $\mathrm{LiMn}_{2} \mathrm{O}_{4}$ cubes, spheres, and pristine $\mathrm{LiMn}_{2} \mathrm{O}_{4}$ at a current rate of $0.5 \mathrm{C}$. (b) Discharge capacity retention of the $\mathrm{LiMn}_{2} \mathrm{O}_{4}$ cubes, spheres, and pristine $\mathrm{LiMn}_{2} \mathrm{O}_{4}$.

$22.6 \%$ and $8.5 \%$, respectively, compared to that of the pristine $\mathrm{LiMn}_{2} \mathrm{O}_{4}$.

It is worth mentioning that the discharge capacity of the $\mathrm{LiMn}_{2} \mathrm{O}_{4}$ cubes at a current density of $0.5 \mathrm{C}$ is very close to the theoretical capacity. Compared to the pristine $\mathrm{LiMn}_{2} \mathrm{O}_{4}$, the capacity increase is very obvious.

Fig. $8 \mathrm{a}$ and $\mathrm{b}$ show the first discharge curves for the $\mathrm{LiMn}_{2} \mathrm{O}_{4}$ cubes and spheres at different rates of 0.5, 1, 2, 5, 10 and 20C, respectively. As can be seen, both the $\mathrm{LiMn}_{2} \mathrm{O}_{4}$ cubes and $\mathrm{LiMn}_{2} \mathrm{O}_{4}$ spheres exhibit two voltage plateaus in their discharge curves, characteristic of typical spinel $\mathrm{LiMn}_{2} \mathrm{O}_{4} \cdot{ }^{44}$ As the current density increases, the curve gradually becomes smoother, such as at 20C. This is due to an increase in cell polarization under high current charge and discharge. ${ }^{45}$
The first discharge capacities of the $\mathrm{LiMn}_{2} \mathrm{O}_{4}$ cubes are 121.3, 116.7, 110.9, 107.4, 101.9 and $96.4 \mathrm{~mA} \mathrm{~h} \mathrm{~g}^{-1}$ at 0.5, 1, 2, 5, 10 and 20C, respectively, while the corresponding values for the $\mathrm{LiMn}_{2} \mathrm{O}_{4}$ spheres are 116.4, 107.8, 105, 101.3, 94.6 and $88.3 \mathrm{~mA} \mathrm{~h} \mathrm{~g}^{-1}$. Fig. 8c shows the rate capabilities of the $\mathrm{LiMn}_{2} \mathrm{O}_{4}$ cubes, spheres, and pristine $\mathrm{LiMn}_{2} \mathrm{O}_{4}$. As the current density increases, the capacities of all of the samples decrease. The pristine $\mathrm{LiMn}_{2} \mathrm{O}_{4}$ exhibits a first discharge capacity of $95.9 \mathrm{~mA} \mathrm{~h} \mathrm{~g}{ }^{-1}$ at $0.5 \mathrm{C}$ and a dramatically decreased value of $35.3 \mathrm{~mA} \mathrm{~h} \mathrm{~g}^{-1}$ at a high current of 20C. However, the $\mathrm{LiMn}_{2} \mathrm{O}_{4}$ cubes and $\mathrm{LiMn}_{2} \mathrm{O}_{4}$ spheres maintain a highly discharge capacity and capacity retention rate during the high current charge and discharge tests. Fig. 8d shows a tendency for the discharge capacity to decrease as the current density increases.
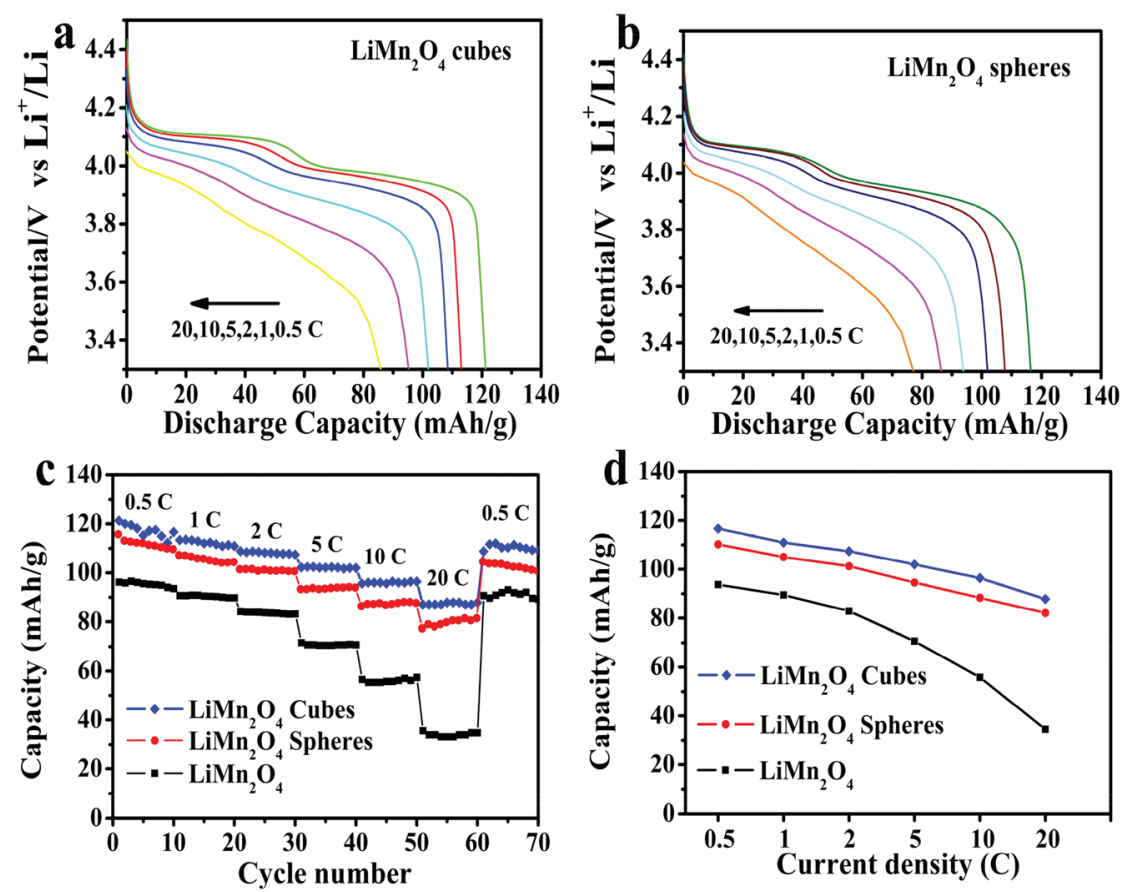

Fig. 8 Discharge curves at different current densities for the $\mathrm{LiMn}_{2} \mathrm{O}_{4}$ (a) cubes and (b) spheres. (c) Rate capabilities of the LiMn $\mathrm{O}_{4}$ cubes, spheres, and pristine $\mathrm{LiMn}_{2} \mathrm{O}_{4}$ and (d) rate capacity retention of the $\mathrm{LiMn}_{2} \mathrm{O}_{4}$ cubes, spheres, and pristine $\mathrm{LiMn}_{2} \mathrm{O}_{4}$. 


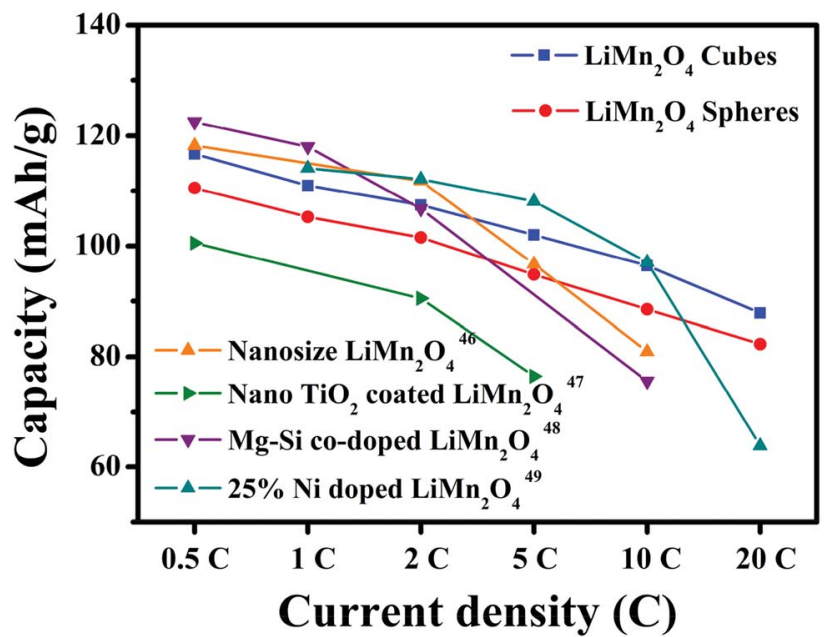

Fig. 9 Discharge capacity compared with that of $\mathrm{LiMn}_{2} \mathrm{O}_{4}$ electrodes reported in ref. 46-49.

The downward trend in the volume of the pristine $\operatorname{LiMn}_{2} \mathrm{O}_{4}$ is quite obvious, and the $\mathrm{LiMn}_{2} \mathrm{O}_{4}$ cubes and spheres show a trend towards lower capacity loss. It is obvious that the $\mathrm{LiMn}_{2} \mathrm{O}_{4}$ cubes and $\mathrm{LiMn}_{2} \mathrm{O}_{4}$ spheres show better structural stability in the high rate current tests. The ordered morphology and loose porous structure of the samples effectively shortens the diffusion distance of $\mathrm{Li}^{+}$in the electrochemical reaction, effectively alleviating the volume change caused by charge and discharge. The data in Fig. 9 is compared to the discharge capacities of $\mathrm{LiMn}_{2} \mathrm{O}_{4}$ electrodes reported in ref. 46-49, where it can be seen that the $\mathrm{LiMn}_{2} \mathrm{O}_{4}$ cube and sphere electrodes exhibited a superior high rate performance at rates of 5-20C.

Fig. 10a depicts the electrical impedance spectra (EIS) using the equivalent circuit by the Zview software. The horizontal axis part is the real part impedance $Z^{\prime}$ and the vertical axis part is the imaginary part impedance $Z^{\prime \prime}$. The EIS spectrum is mainly composed of a semicircular curve in the high frequency and medium frequency regions and a straight line in the low frequency region. The intercept of the arc curve and the horizontal axis is the ohmic resistance $R_{\mathrm{s}}$, the semicircular curve of the high frequency and medium frequency regions represents the charge transfer resistance $R_{\mathrm{ct}}$, and the straight line in the low frequency region and the $\mathrm{Li}^{+}$in the $\mathrm{LiMn}_{2} \mathrm{O}_{4}$ electrode material relate to the spread, represented by the Warburg impedance $\left(Z_{\mathrm{w}}\right){ }^{15,50,51}$ The Zview software is used to fit the impedance parameters using the equivalent circuit to obtain the parameters. The $R_{\text {ct }}$ values of the $\mathrm{LiMn}_{2} \mathrm{O}_{4}$ cubes, spheres, and pristine $\mathrm{LiMn}_{2} \mathrm{O}_{4}$ were calculated to be 176.6, 193.2, and $219.7 \Omega$, respectively, and the Warburg coefficient and diffusion coefficient of lithium ions in the low frequency region were calculated using the following equation: ${ }^{15,50}$

$$
\begin{gathered}
|Z|=R_{\mathrm{s}}+R_{\mathrm{ct}}+\sigma_{\mathrm{w}} \omega^{-1 / 2} \\
D_{\mathrm{Li}^{+}}=R^{2} T^{2} / 2 A^{2} n^{4} F^{4} C^{2} \sigma^{2}
\end{gathered}
$$

In eqn (9), $\sigma$ is the Warburg impedance coefficient and $\omega$ is the angular frequency. In eqn (10), $R$ is the molar gas constant 8.314 $\mathrm{J} \mathrm{mol}^{-1} \mathrm{~K}^{-1}, T$ is the temperature in Kelvin, $A$ is the surface area of the electrode material, $n$ is the number of electrons transferred during charging and discharging, $F$ is the Faraday constant (96 485 $\mathrm{C} \mathrm{mol}^{-1}$ ), and $C$ is the molar concentration of lithium ions $\left(0.0238 \mathrm{~mol} \mathrm{~cm} \mathrm{~cm}^{-1-3}\right.$ derived from the relationship between the $\mathrm{LiMn}_{2} \mathrm{O}_{4}$ density and relative molecular mass). ${ }^{52,53}$ Fig. 10b shows the relationship between the reciprocal square root of the angular frequency of the low frequency region and the $Z^{\prime}$ after the data is fitted. The slope of the fitted straight line is the Warburg coefficient. The Warburg coefficients of the $\mathrm{LiMn}_{2} \mathrm{O}_{4}$ cubes, spheres, and pristine $\mathrm{LiMn}_{2} \mathrm{O}_{4}$ were calculated to be $357,546.4$ and $913.3 \Omega \mathrm{S}^{1 / 2}$, respectively. The diffusion coefficients of the lithium ions were then calculated according to eqn (10). The diffusion coefficients of the $\mathrm{LiMn}_{2} \mathrm{O}_{4}$ cubes, spheres, and pristine $\mathrm{LiMn}_{2} \mathrm{O}_{4}$ were calculated to be $2.074 \times$ $10^{-16}, 8.855 \times 10^{-17}$, and $3.169 \times 10^{-17} \mathrm{~cm}^{2} \mathrm{~s}^{-1}$, respectively. Therefore, the results of the tests and calculations show that the $\mathrm{LiMn}_{2} \mathrm{O}_{4}$ cubes and spheres exhibit lower charge transfer resistance and better lithium ion diffusion ability than the comparative pristine sample. This revealed that the morphology control improved the charge transfer resistance and the diffusion of lithium ions.
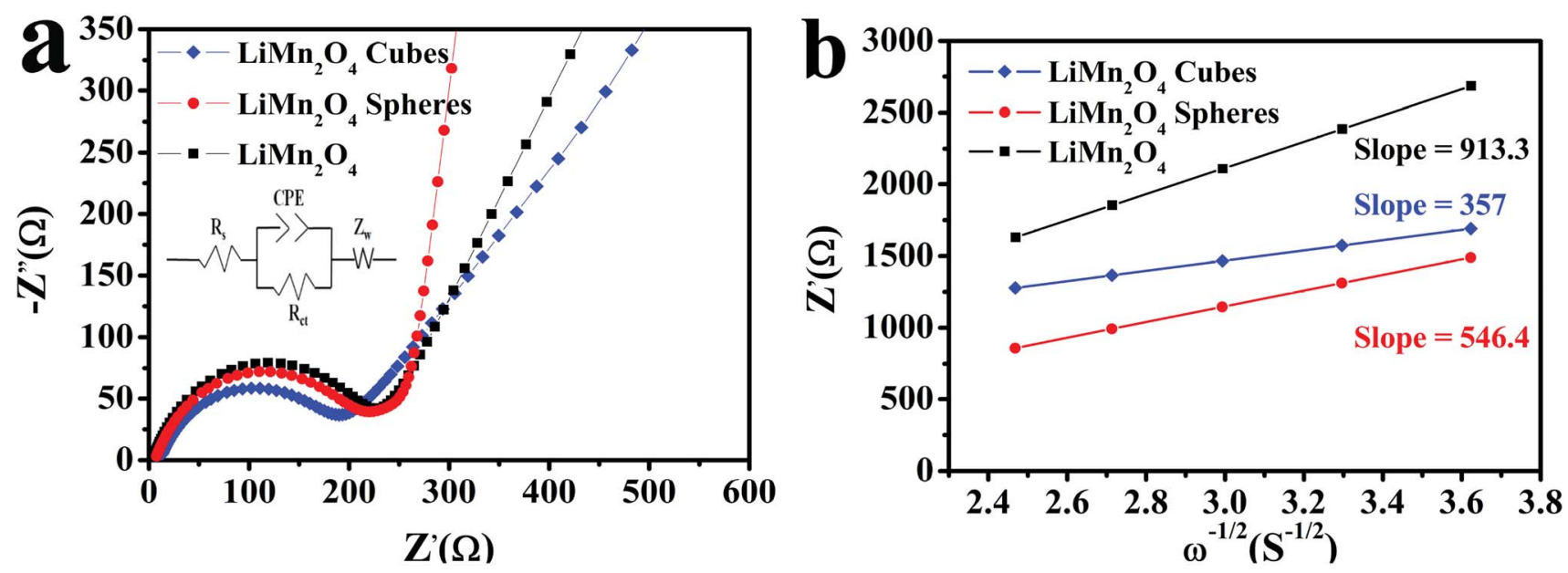

Fig. 10 (a) The fitted EIS curves of the $\mathrm{LiMn}_{2} \mathrm{O}_{4}$ cubes, spheres, and pristine $\mathrm{LiMn}_{2} \mathrm{O}_{4}$ and (b) fitting line function diagram of $Z^{\prime}$ and $\omega^{-1 / 2}$. 
Table 1 Data obtained for the carbonate precursor or the same morphology $\mathrm{LiMn}_{2} \mathrm{O}_{4}$ synthesized using different methods

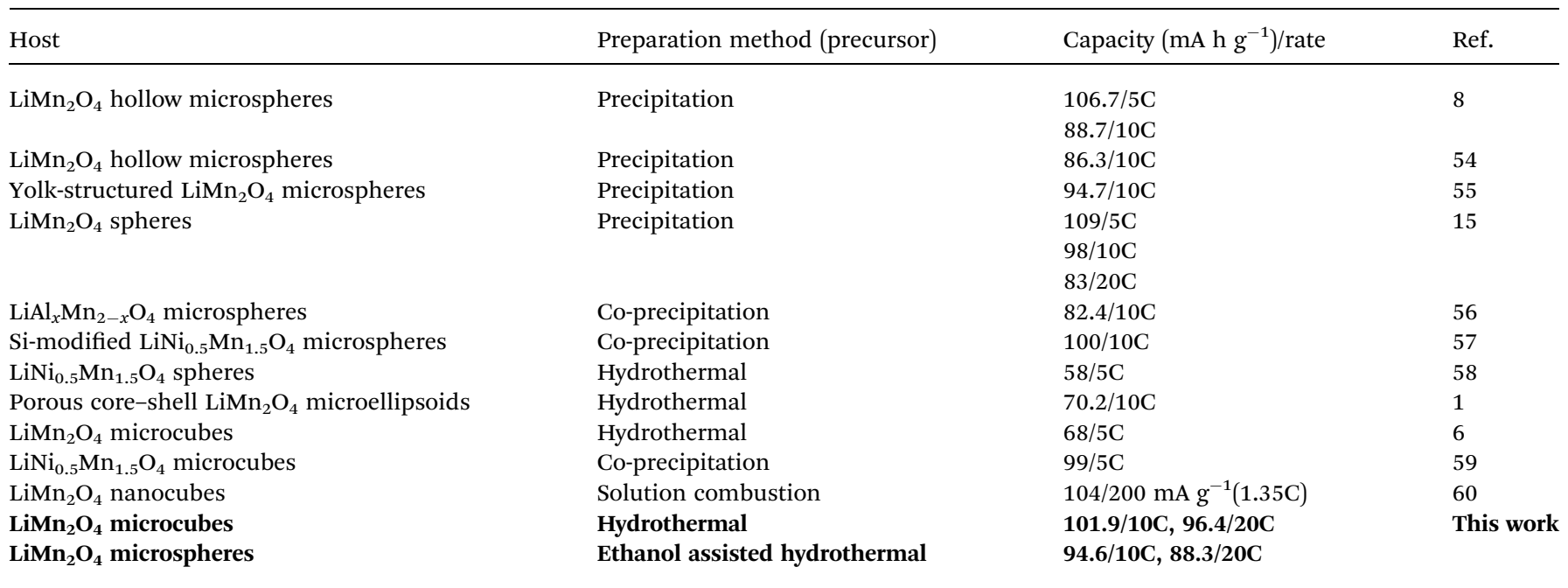

Compared with the data obtained for the carbonate precursor or the same morphology synthesized using different methods (as shown in Table 1), it could be seen that the hydrothermal and ethanol assisted hydrothermal routes are the ideal routes to use to synthesize a precursor with a different morphology and final products that have a better electrochemical performance. Using this method, the carbonate precursor can be obtained under mild reaction conditions, and a better discharge capacity of the $\mathrm{LiMn}_{2} \mathrm{O}_{4}$ electrode charge/ discharge can be achieved at a higher current density.

\section{Conclusions}

We have adopted a synthetic strategy for preparing $\mathrm{MnCO}_{3}$ precursors with different morphologies. $\mathrm{MnCO}_{3}$ cubes and spheres were prepared using the crystal planes (104) in the structure of $\mathrm{MnCO}_{3}$ as the synthetic entry point. After thermal decomposition and lithiation, a $\mathrm{LiMn}_{2} \mathrm{O}_{4}$ cathode material was obtained. Even if the lithium source was $\mathrm{Li}_{2} \mathrm{CO}_{3}$, the morphology was still largely retained after high-temperature calcination. The macro-ordered surfaces of the prepared $\mathrm{LiMn}_{2} \mathrm{O}_{4}$ cubes and spheres are porous, which provides a space for the diffusion of lithium ions, significantly improving the lithium-ion solid-phase diffusion ability. And, the electrochemical performance was remarkably improved, especially the rate performance, without the need for any coating and doping with other elements. This synthetic strategy can be applied to the synthesis of other oxides and in other fields.

\section{Conflicts of interest}

There are no conflicts to declare.

\section{Acknowledgements}

This research has been supported by the Natural Science Foundation of Jilin Province (No. 20170101128JC), the Youth Foundation of Changchun University of Science and
Technology (no. XQNJJ-2014-13, XJJLG-2014-10), the Industrial Technology Research and Development Project of Jilin Province Development and Reform Commission (2017C052-4), and the Science and Technology Planning Project of Changchun City (no. 2013064).

\section{References}

1 J. Deng, J. Pan, Q. Yao, Z. Wang, H. Zhou and G. Rao, J. Power Sources, 2015, 278, 370-374.

2 F. Marchini, E. J. Calvo and F. J. Williams, Electrochim. Acta, 2018, 269, 706-713.

3 J. Wang, Y.-y. Yu, B.-h. Wu, W.-q. Lin, J.-y. Li and J.-b. Zhao, J. Mater. Chem. A, 2015, 3, 2353-2360.

4 Y. Deng, Y. Zhou, Z. Shi, X. Zhou, X. Quan and G. Chen, J. Mater. Chem. A, 2013, 1, 8170-8177.

5 G. Xu, Z. Liu, C. Zhang, G. Cui and L. Chen, J. Mater. Chem. A, 2015, 3, 4092-4123.

6 Y. Wu, Z. Wen, H. Feng and J. Li, Small, 2012, 8, 858-862.

7 W. Sun, H. Liu, Y. Liu, G. Bai, W. Liu, S. Guo and X. Z. Zhao, Nanoscale, 2015, 7, 13173-13180.

8 L. Zhou, X. Zhou, X. Huang, Z. Liu, D. Zhao, X. Yao and C. Yu, J. Mater. Chem. A, 2013, 1, 837-842.

9 S. Chen, Z. Chen and C. Cao, Electrochim. Acta, 2016, 199, 5158.

10 M. D. Levi and D. Aurbach, J. Phys. Chem. B, 1997, 101, 46414647.

11 S.-T. Myung, K. Amine and Y.-K. Sun, J. Power Sources, 2015, 283, 219-236.

12 A. K. Jahja, M. Panitra, W. Honggowiranto, S. Mustofa and Y. Yunasfi, Ionics, 2015, 22, 219-227.

13 Y.-L. Ding, J. Xie, G.-S. Cao, T.-J. Zhu, H.-M. Yu and X.-B. Zhao, Adv. Funct. Mater., 2011, 21, 348-355.

14 H. Zhao, F. Li, X. Liu, W. Xiong, B. Chen, H. Shao, D. Que, Z. Zhang and Y. Wu, Electrochim. Acta, 2015, 166, 124-133.

15 Y. Wang, X. Shao, H. Xu, M. Xie, S. Deng, H. Wang, J. Liu and H. Yan, J. Power Sources, 2013, 226, 140-148. 
16 X. Zhu, X. Li, Y. Zhu, S. Jin, Y. Wang and Y. Qian, J. Power Sources, 2014, 261, 93-100.

17 Z. Zou, Z. Li, H. Zhang, X. Wang and C. Jiang, J. Mater. Sci. Technol., 2017, 33, 781-787.

18 R. Xing, R. Li, Y. Xu, B. Li, J. Liu, S. Liu, D. Luo and L. Mao, Ceram. Int., 2017, 43, 14426-14430.

19 J. Zhao, Y. Li, Z. Xu, D. Wang, C. Ban and H. Zhang, Electrochim. Acta, 2018, 289, 72-81.

20 X. Xiao, J. Lu and Y. Li, Nano Res., 2010, 3, 733-737.

21 S. Huang, H. Wu, P. Chen, Y. Guo, B. Nie, B. Chen, H. Liu and Y. Zhang, J. Mater. Chem. A, 2015, 3, 3633-3640.

22 Y. Wu, J. Zhang and C. Cao, Nano Res., 2017, 11, 246-253.

23 Y. Tang, Y. Lu and G. Luo, Ind. Eng. Chem. Res., 2017, 56, 10036-10043.

24 J. Li, C. Cao, X. Xu, Y. Zhu and R. Yao,J. Mater. Chem. A, 2013, 1, 11848-11852.

25 F. C. Meldrum and H. Colfen, Chem. Rev., 2008, 108, 43324432.

26 K. K. Sand, J. D. Rodriguez-Blanco, E. Makovicky, L. G. Benning and S. L. S. Stipp, Cryst. Growth Des., 2011, 12, 842-853.

27 K. S. Keller, M. H. Olsson, M. Yang and S. L. Stipp, Langmuir, 2015, 31, 3847-3853.

28 A. M. Bano, P. M. Rodger and D. Quigley, Langmuir, 2014, 30, 7513-7521.

29 K. K. Sand, M. Yang, E. Makovicky, D. J. Cooke, T. Hassenkam, K. Bechgaard and S. L. Stipp, Langmuir, 2010, 26, 15239-15247.

30 D. J. Cooke, R. J. Gray, K. K. Sand, S. L. Stipp and J. A. Elliott, Langmuir, 2010, 26, 14520-14529.

31 S. S. Hakim, M. H. M. Olsson, H. O. Sorensen, N. Bovet, J. Bohr, R. Feidenhans'l and S. L. S. Stipp, Sci. Rep., 2017, 7, 7592 .

32 N. Bovet, M. Yang, M. S. Javadi and S. L. Stipp, PCCP Phys. Chem. Chem. Phys., 2015, 17, 3490-3496.

33 K. K. Sand, M. Yang, E. Makovicky, D. J. Cooke, T. Hassenkam, K. Bechgaard and S. L. Stipp, Langmuir, 2010, 26, 15239-15247.

34 H. Imada, K. Kimura and H. Onishi, Langmuir, 2013, 29, 10744-10751.

35 W.-H. Ryu, S.-J. Lim, W.-K. Kim and H. Kwon, J. Power Sources, 2014, 257, 186-191.

36 Z. Li, J. Xu, X. Chen, Q. Zhou and T. Shang, Colloid Polym. Sci., 2011, 289, 1643-1651.

37 J. D. H. Donnay and D. Harker, Am. Mineral., 1937, 22, 446467.
38 H. Colfen and S. Mann, Angew. Chem., 2003, 42, 2350-2365. 39 X. Duan, J. Lian, J. Ma, T. Kim and W. Zheng, Cryst. Growth Des., 2010, 10, 4449-4455.

40 F. R. Massaro, L. Pastero, M. Rubbo and D. Aquilano, J. Cryst. Growth, 2008, 310, 706-715.

41 R. Wang, X. Li, Z. Wang, H. Guo, T. Hou, G. Yan and B. Huang, J. Alloys Compd., 2015, 618, 349-356.

42 Y. Wu, C. Cao, J. Zhang, L. Wang, X. Ma and X. Xu, ACS Appl. Mater. Interfaces, 2016, 8, 19567-19572.

43 H. B. Lin, Y. M. Zhang, H. B. Rong, S. W. Mai, J. N. Hu, Y. H. Liao, L. D. Xing, M. Q. Xu, X. P. Li and W. S. Li, J. Mater. Chem. A, 2014, 2, 11987.

44 K.-W. Nam, W.-S. Yoon, H. Shin, K. Y. Chung, S. Choi and X.-Q. Yang, J. Power Sources, 2009, 192, 652-659.

45 Y. L. Ding, J. Xie, G. S. Cao, T. J. Zhu, H. M. Yu and X. B. Zhao, J. Phys. Chem. C, 2011, 115, 9821-9825.

46 S. Li, D. Lei, Y. Xue, S. Geng and X. Cui, Ionics, 2017, 23, 1979-1984.

47 Y. Shang, X. Lin, X. Lu, T. Huang and A. Yu, Electrochim. Acta, 2015, 156, 121-126.

48 H. Zhao, F. Li, X. Liu, C. Cheng, Z. Zhang, Y. Wu, W. Xiong and B. Chen, Electrochim. Acta, 2015, 151, 263-269.

49 Z. Moorhead-Rosenberg, A. Huq, J. B. Goodenough and A. Manthiram, Chem. Mater., 2015, 27, 6934-6945.

50 T. Shi, Y. Dong, C.-M. Wang, F. Tao and L. Chen, J. Power Sources, 2015, 273, 959-965.

51 D. Guo, Z. Chang, H. Tang, B. Li, X. Xu, X.-Z. Yuan and H. Wang, Electrochim. Acta, 2014, 123, 254-259.

52 L. J. Xi, H.-E. Wang, Z. G. Lu, S. L. Yang, R. G. Ma, J. Q. Deng and C. Y. Chung, J. Power Sources, 2012, 198, 251-257.

53 X. Wang, H. Hao, J. Liu, T. Huang and A. Yu, Electrochim. Acta, 2011, 56, 4065-4069.

54 Y. Mao, S. Xiao and J. Liu, Mater. Res. Bull., 2017, 96, 437442.

55 Y. Qiao, Si. Li, Y. Yu and C. Chen, J. Mater. Chem. A, 2013, 1, 860-867.

56 X. Yi, X. Wang, B. Ju, Q. Wei, X. Yang, G. Zou, H. Shu and L. Hu, J. Alloys Compd., 2014, 604, 50-56.

57 S. Nageswarana, M. Keppeler, S. Kim and M. Srinivasan, J. Power Sources, 2017, 346, 89-96.

58 J. Cheng, X. Li, Z. Wang and H. Guo, Ceram. Int., 2016, 42, 3715-3719.

59 Y. Li, J. Wang, Z. Zhou, Q. Yao, Z. Wang, H. Zhou and J. Deng, Int. J. Electrochem. Sci., 2019, 14, 2822-2832.

60 S. A. Akhoon, A. H. Sofi, S. Rubab and M. A. Shan, J. Electron. Mater., 2017, 46, 992-998. 